NEUROLOGICAL PICTURE

\title{
Gardner's hypothesis and magnetic resonance imaging
}

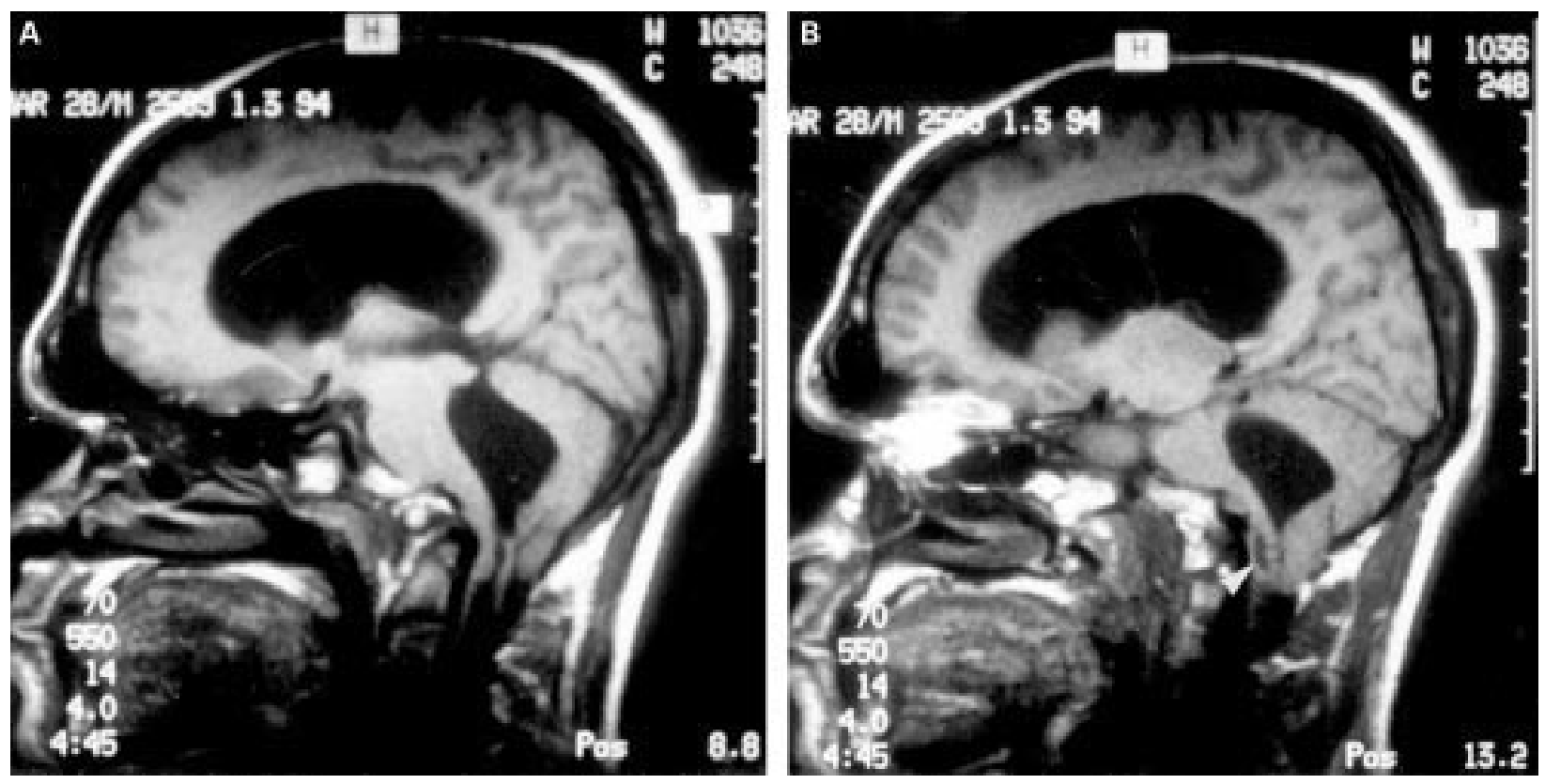

T1 weighted sagittal images at 4.4 interslice gap of a patient with syringomyelia, showing the essentials of Gardner's hypothesis: (1) hindbrain herniation with outflow obstruction; (2) hydrocephalus with the fourth ventricle connecting to a dilated central canal of the cord, (3) extension of the central cavity into the brainstem, constituting a syringobulbia (arrowhead). Cine mode showed pulsatile CSF flow across the fourth ventricle into the central canal and syrinx.

ANOOP KOHLI

Department of Neurology

RAKESH K GUPTA

Department of Radiology (MRI), Sanjay

Gandhi PGI, Lucknow, India-226014

Correspondence to: Dr Anoop Kohli, K-11, Department of Neurology, Henry Ford Hospital, 2799, W Grand Boulevard, Detroit, Michigan-48202-2689, USA. 